\title{
Analytic Network Process for Developing Relative Weight of Wastewater Treatment Technology Selection
}

\author{
Lazim Abdullah $^{1} \&$ Nurul Atiqah Abd Rahman ${ }^{1}$ \\ ${ }^{1}$ School of Informatics and Applied Mathematics, Universiti Malaysia Terengganu, Malaysia \\ Correspondence: Lazim Abdullah, School of Informatics and Applied Mathematics, Universiti Malaysia \\ Terengganu, Kuala Terengganu, 21030, Malaysia. Tel: 609-668-3335. E-mail: lazim_m@umt.edu.my
}

Received: December 29, 2016

Accepted: January 8, 2017

Online Published: April 8, 2017

doi:10.5539/mas.v11n5p64

URL: https://doi.org/10.5539/mas.v11n5p64

\begin{abstract}
Selecting the best wastewater treatment (WWT) technology requires a thorough qualitative and quantitative evaluation of multi-dependence criteria. A network based method is one of the many possible techniques that able to handle multi-dependence criteria in the selection. This paper proposes relative importance weights of alternatives in selecting the WWT technology using the analytic network process (ANP) in Terengganu Malaysia. The ANP is applied to establish the relative weights of alternatives based on criteria and sub-criteria that available in the WWT technology selection. Two faculty members attached to a public university and an engineer in Malaysian government agency were interviewed to provide evaluation within the framework of ANP. Inner dependence and outer dependence analysis of ANP are fully utilised to establish relative importance weights of alternatives. The experiment result reveals that the relative importance weights of the three alternatives are $0.3074,0.2795$ and 0.2447 . The alternative 'Composting' has decided as the most suitable technology in WWT which provides the highest relative importance weight among all the three alternatives. The results would be a great significance for the practical implementation of the WWT technology selection.
\end{abstract}

Keywords: analytic network process, decision making, wastewater treatment, relative weight, pair-wise comparison

\section{Introduction}

\subsection{Background}

Over the past century, there has been a dramatic increase in world population and economic growth. In the midst of these increasing trends, one of the basic infrastructures that really in a pressing need is treated water. Sustainable treated water infrastructure is essential so that the people will be able to consume clean and safe water. Treated water infrastructure may contribute in improvising the environmental, economic and social health of the nation's communities (Ross et al., 2012). In order to protect the environment from the negative impact of wastewater as well as to sustain a healthy life, it urgently important to treat wastewater in a good way with the use of effective technology. Wastewater treatment (WWT) technology is inevitable despite its highly operating cost and less effective results. Among the popular technologies in WWT are anaerobic digestion, phytoremediation, and composting (Bottero et al, 2011). Selecting the ideal technology is very tricky due many considerations need to be accounted concurrently, especially from technology specification perspective and also from multiple intangible criteria that characterised the selection. It is more difficult if locations or regions where the technology should be deployed are also considered. Therefore, selecting the ideal WWT technology is not a straight forward process. There are many criteria that need to be considered for selecting the ideal WWT technology. However the main three criteria that normally available in the literature are economical aspect, environmental aspect, and technological aspect (Bottero et al, 2011). In other words, WWT technology selection can be regarded as a multi-criteria or attributes decision making problem. The method used in solving the problem must be flexible enough as to allow several criteria being taken into account simultaneously in a complex situation. The method used in analyzing these criteria and alternatives must help decision-makers to express their different options, which reflect the opinions of the actor involved Figueira et al., (2005).

\subsection{Motivation and Objective}

In decision analysis, there are many decision problems that cannot be analyzed hierarchically due to their 
interaction and dependencies of higher-level elements in a hierarchy on lower-level elements. In order to overcome this issue, Saaty (1996) proposed the method of analytic network process (ANP) where dependencies and interactions among criteria are taken care of. Unlike many other decision making methods, the ANP is rather represented by a network. Furthermore, the ANP is constructed based on feedback in clusters (Saaty, 1996). Many researchers had shown their interest over the applications of ANP. The ANP has been widely applied in strategic policy planning (Ulutas, 2005), marketing and logistics (Agarwal, et al., 2006), economics and finance (Niemura and saaty, 2004), and civil engineering (Neaupane and Piantanakulchai, 2006). There was also research on territorial and environmental assessment (Promentilla, et al., 2006; Bottero, et al., 2008; Wolfslehner, and Vacik, 2008). In waste management, ANP was used to prioritize and select the suitable municipal solid waste disposal method(Khan and faisal, 2008). Banar et al., (2007), used ANP to choose one out of four alternatives regarding landfill sites in Turkey, while Tuzkaya et al., (2008) used ANP to locate the undesirable facilities. To the best of the author's knowledge, there were a limited number of applications of ANP to WWT technology selection. This paper aims to develop a decision for selecting the WWT technology based on relative importance weights that established from the ANP. In contrast to previous works, this model considers the inner dependence and outer dependence among the criteria that give an additional effect to the model. The rest of this paper is organized as follows. Section 2 provides reviews regarding the methods used for WWT technologies. Section 3 presents computational steps of ANP. Section 4 presents the implementation of ANP to a case of WWT technology selection. Section 5 concludes

\section{Literature Review}

The literature review has been carried out by referring to leading journal databases. The literature has been reviewed from the perspective of various methods used for WWT techniques or selections. There are a handful of research that specifically conducted on the WWT technology selections. The various methods used for WWT selections are summarized in Table 1 .

Table 1. Methods used for WWT technology

\begin{tabular}{|c|c|}
\hline $\begin{array}{l}\text { Research } \\
\text { articles }\end{array}$ & Contributions \\
\hline $\begin{array}{l}\text { Plakas et al., } \\
(2016)\end{array}$ & $\begin{array}{l}\text { The participatory method called simple multi-attribute rating technique exploiting ranks has } \\
\text { been employed for assigning weights to selected sustainability indicators. The multi-criteria } \\
\text { analysis gives the opportunity to researchers, designers and decision-makers to examine } \\
\text { decision options in a multi-dimensional fashion. Four tertiary WWT technologies were } \\
\text { assessed regarding their sustainability performance in producing recycled wastewater. }\end{array}$ \\
\hline $\begin{array}{l}\text { Kalbar et al., } \\
(2012)\end{array}$ & $\begin{array}{l}\text { The multiple-attribute decision making methodology TOPSIS has been developed and } \\
\text { applied to the selection of wastewater treatment alternatives. The four most commonly used } \\
\text { WWT technologies for treatment of municipal wastewater in India are ranked in various } \\
\text { scenarios. The articulated scenarios depict the most commonly encountered decision-making } \\
\text { situations in addressing technology selection for wastewater treatment in India. A widely } \\
\text { used compensatory technique, TOPSIS, has been selected to rank the WWT alternatives. }\end{array}$ \\
\hline
\end{tabular}

Abdullah, L. Fuzzy simple additive weighting has been used to identify the most suitable WWT (2015) technology. Three decision makers were appointed to evaluate and provide information regarding the WWT technologies and its affiliated criteria.

Ilangkumaran et The application of hybrid multi-criteria decision-making technique for the selection of WWT al., (2014) technology for treating wastewater. The proposed approach is based on fuzzy analytical hierarchy process and hierarchy grey relation analysis technique. The fuzzy analytical hierarchy process is used to determine the weights of criteria and then ranking of the WWT technology alternatives is determined by grey relation analysis technique.

Ilangkumaran et The methods of Analytical Hierarchy Process under fuzzy environment, Preference Ranking al., (2013) Organization Method for Enrichment Evaluation and hierarchy Grey Relation Analysis techniques have been used for selection of WWT technology for treating wastewater.

Molinos-Senante The analytical hierarchical process has been used to assign weights of indicators of global et al., (2014) sustainability of the WWT technologies. The proposed approach contributes to ease of interpretation of a complex problem such as the selection of the most sustainable WWT alternative. 
It is noticed that most of the methods are not considered the dependencies among criteria and sub-criteria of WWT. The following section provides a computational procedure of ANP where dependencies among criteria and sub-criteria are purposely managed in the computation.

\section{Computational Procedure}

The ANP can be represented by super-matrix by evaluating the elements in the network on other elements in the network. It consists of two-dimensional element-by-element matrix that may change the relative importance weight to build a new overall super-matrix which consists of eigen-vector of the changed relative importance weights. The ANP can be divided into four main steps namely model construction and problem structuring, pair-wise comparison matrices and its priority vectors construction, super-matrix formation, and selection of the best alternatives (Yuksel and Dagdeviren, 2007; Saaty, 1996). The main steps are described as follows.

Step 1: Model construction and problem structuring.

Identify the sub-criteria for each criterion and determine the alternative strategies according to sub-criteria.

Step 2: Determine degree of importance and normalized weight.

Assume that there is no dependent among the criteria. Then, determine the importance degrees of the criteria with a 1-9 scale by constructing pair-wise comparison matrix (see Table 2). Here, $w_{l}$ is calculated where $w_{l}$ is the normalized weight of the pair-wise comparison matrix of criteria with respect to goal.

Table 2. The pair-wise comparison scale

\begin{tabular}{lll}
\hline $\begin{array}{l}\text { Intensity of } \\
\text { Importance }\end{array}$ & Definition & Explanation \\
\hline 1 & Equal Importance & Two criteria contribute equally to the objective \\
3 & Moderate Importance & Experience and judgment strongly favor one criteria over another \\
5 & Strong Importance & Experience and judgment strongly favor one criteria over another \\
7 & Very Strong & The criteria is strongly favored and its importance is demonstrated in \\
practice
\end{tabular}

To compute the eigen-vector (normalized weight), the row sum for each row, sum of column of each row, and sum of the matrix must be computed beforehand. Divide each row sum by the sum of the matrix. Eigenvector, $x$ (normalised weights) is computed using the equation (1).

$$
\text { Eigen vector }=x=A_{i j}=\frac{\sum_{i=1}^{n}\left(w_{1} / w_{1} \times w_{1} / w_{2} \times \ldots \times w_{1} / w_{n}\right)^{1 / n}}{\sum\left[\sum_{i=1}^{n}\left(w_{1} / w_{1} \times w_{1} / w_{2} \times \ldots \times w_{1} / w_{n}\right)^{1 / n}\right]}
$$

where $w_{i}$ is the sum of row for pair-wise comparison and $n$ is the size of matrix.

Step 3: Determine the inner dependence matrix of each criterion with respect to the other criteria by constructing the pair-wise comparison matrix of inner dependence among the criteria.

Here, $w_{2}$ is calculated where $w_{2}$ is the normalized weight obtained from each inner dependence matrix of each criterion with respect to the other criteria.

Step 4: Determine the inner dependence weights of the criteria.

Here, $w_{\text {criteria }}$ is calculated such that $w_{\text {criteria }}=w_{2} \times w_{1}$ which are obtained from Step 2 and Step 3.

Step 5: Determine the local importance degrees of the sub-criterion by constructing the pair-wise comparison matrix of sub-criteria with respect to each criterion.

Here, $w_{\text {sub-criteria(local) }}$ is calculated. It is obtained from the normalized weight of pair-wise comparison matrix of sub-criteria with respect to each criterion.

Step 6: The global importance degree of the sub-criteria is determined. 
Here, $w_{\text {sub-criteria(global) }}=w_{\text {criteria }} \times w_{\text {sub-criteria(local) }}$ was calculated.

Step 7: The importance degrees of the alternatives with respect to each sub-criterion are determined by constructing the pair-wise comparison matrix on alternatives with respect to each sub-criterion.

Here, $w_{4}$ is calculated. It is obtained from the normalized weight of pair-wise comparison matrix on alternatives with respect to each sub-criterion.

Step 8: The overall weights of the alternatives which reflect the inter-relationships within criteria are determined.

Here, $w_{\text {alternatives }}=w_{4} \times w_{\text {sub-criteria(global) }}$ is calculated.

From the value of $w_{\text {alternatives, }}$, the alternative with the largest overall weight is selected as the best alternative. The implementation of these steps is illustrated in the next section.

\section{Implementation}

It has been suggested that alternatives, criteria and sub-criteria in the WWT technology selection are the key components of a multi-criteria decision problem. There exist dependencies between groups of criteria and alternatives which need to be analyzed. Detailed analysis to search for inter-relationships between clusters of WWT technology priority is imperative. This paper proposes an experiment that seeking a decision for prioritizing the selection of WWT technology based on the relative weights of alternatives using the ANP. Linguistic data were collected from three decision makers (DMs) via structured interviews. The selection of DMs was carefully made in making sure that they are highly regarded and experts in WWT technology. The three DMs comprise two faculty members and one chemical engineer. The two faculty members were attached to Department of Environmental Engineering, Faculty of Science at a public university in Malaysia. The engineer was attached to Kuala Terengganu Municipality Council in Peninsular Malaysia. Their judgments were made based on the need for WWT in the state of Terengganu Malaysia using the 1-9 scale of the ANP. Intensity and explanations of the scales can be retrieved from Saaty (1996). In addition to the scale, another special feature in the ANP is reciprocal values. If any value between 1-9 assigned to it when compared with $j$, then $j$ has its reciprocal value when compared with $i$. In this experiment, the selected alternatives, criteria, and sub-criteria are as retrieved from Bottero et al., (2011). This study seeks to propose the rank order of the ideal WWT technologies by applying the ANP. The implementation of this case using the ANP method is presented as follows.

Step 1: Model construction and problem structuring.

The WWT system problem is defined by identifying goal, criteria, sub-criteria and alternatives. The structure of the problem is shown in Figure 1.

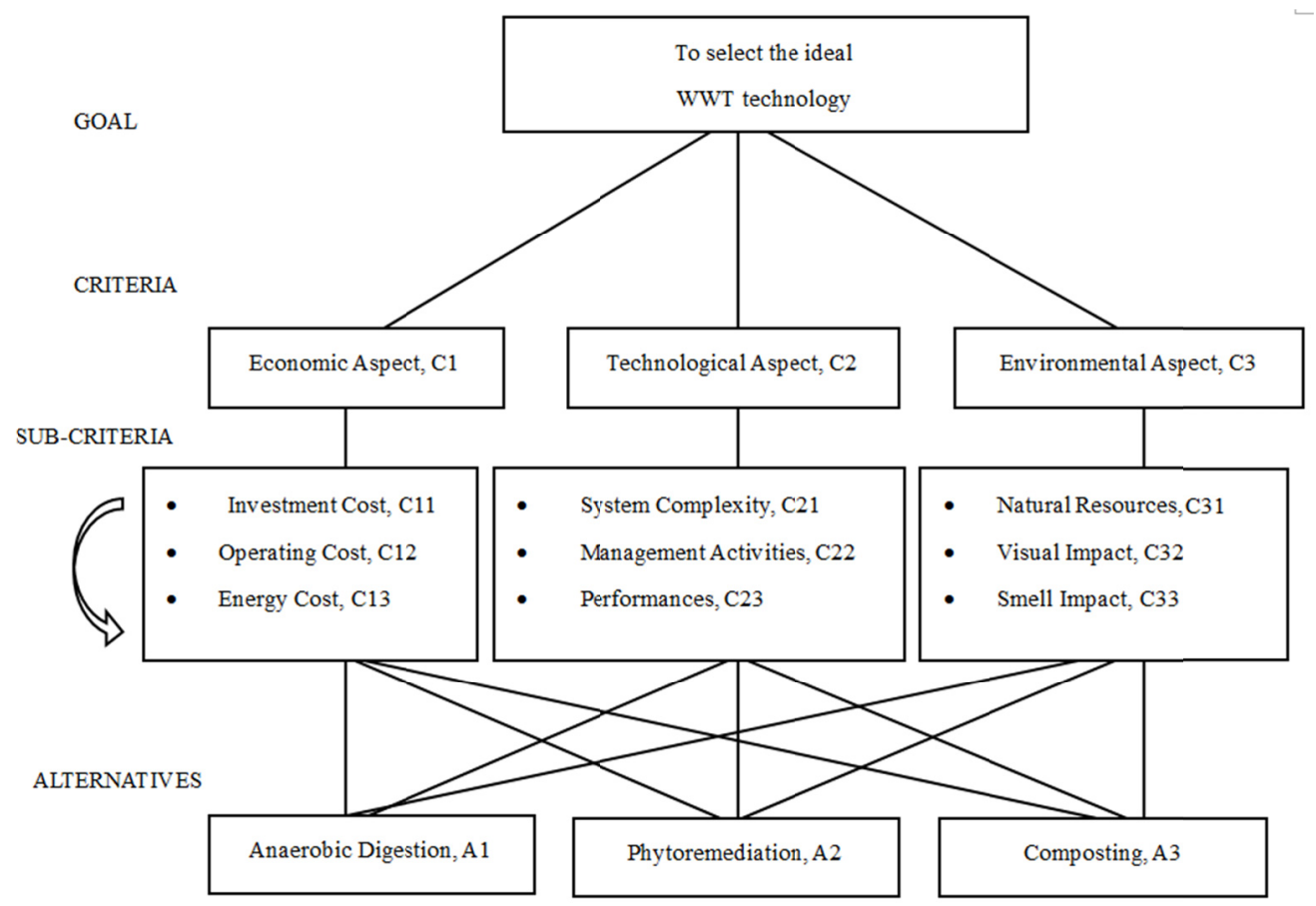

Figure 1. Framework of the ANP for WWT technology selection problem 
Step 2: Determine degree of importance and normalized weight.

The importance of criteria was determined using 1-9 scale. Here, $\mathrm{w}_{1}$ is obtained. The pair-wise comparison of the criteria with respect to goal was constructed. The weights of criteria are shown in Table 3.

Table 3. Pair-wise comparison of alternatives with respect to goal

\begin{tabular}{llllll}
\hline Goal & C1 & C2 & C3 & Row Sum & Weight \\
\hline C1 & 1 & 5 & 3 & 9.000 & 0.60538 \\
C2 & $1 / 5$ & 1 & $1 / 3$ & 1.533 & 0.10314 \\
C3 & $1 / 3$ & 3 & 1 & 4.333 & 0.29148 \\
\hline & & & & 14.867 & 1.000 \\
\hline
\end{tabular}

Therefore, normalized weights for criteria can be written as,

\begin{tabular}{lrr}
\hline & $\mathrm{C} 1$ & 0.60538 \\
\hline$w_{1}=$ & $\mathrm{C} 2$ & $=$ \\
& $\mathrm{C} 3$ & 0.10314 \\
& & 0.29148 \\
\hline
\end{tabular}

Step 3: The inner dependence matrix among criteria is determined by analyzing the effect of each criterion to other criteria using pair-wise comparison matrix. Their normalized weights are summarized as $w_{2}$. Table 4, Table 5 and Table 6 show the inner dependence matrix of criteria with respect to other criteria.

Table 4. Inner dependence matrix of criteria with respect to $\mathrm{C} 1$

\begin{tabular}{lllll}
\hline C1 & C2 & C3 & Row Sum & Weight \\
\hline C2 & 1 & 5 & 6.0000 & 0.8333 \\
$\mathrm{C} 3$ & $1 / 5$ & 1 & 1.2000 & 0.1667 \\
\hline & & & 7.2000 & 1.0000 \\
\hline
\end{tabular}

Table 5. Inner dependence matrix of criteria with respect to $\mathrm{C} 2$

\begin{tabular}{lllll}
\hline $\mathrm{C} 2$ & $\mathrm{C} 1$ & $\mathrm{C} 3$ & Row Sum & Weight \\
\hline $\mathrm{C} 1$ & 1 & 7 & 8.0000 & 0.8750 \\
$\mathrm{C} 3$ & $1 / 7$ & 1 & 1.1429 & 0.1250 \\
\hline & & & 9.1429 & 1.0000 \\
\hline
\end{tabular}

Table 6. Inner dependence matrix of criteria with respect to $\mathrm{C} 3$

\begin{tabular}{lllll}
\hline C3 & C1 & C2 & Row Sum & Weight \\
\hline C1 & 1 & 9 & 10.0000 & 0.9000 \\
C2 & $1 / 9$ & 1 & 1.1111 & 0.1000 \\
\hline & & & 11.1111 & 1.0000 \\
\hline
\end{tabular}

So, the weight for inner dependence for criteria $\mathrm{C} 1, \mathrm{C} 2$ and $\mathrm{C} 3$ are summarized as;

\begin{tabular}{lllll}
\hline & & $\mathrm{C} 1$ & $\mathrm{C} 2$ & $\mathrm{C} 3$ \\
\hline \multirow{3}{*}{$w_{2}=\mathrm{C} 1$} & 0.0000 & 0.8750 & 0.9000 \\
& $\mathrm{C} 2$ & 0.8333 & 0.0000 & 0.1000 \\
$\mathrm{C} 3$ & 0.1667 & 0.1250 & 0.0000 \\
\hline
\end{tabular}

Step 4: The interdependence weight of the criteria is computed. The $w_{\text {criteria }}$ is computed as follows;

\begin{tabular}{rllllll}
\hline$w_{\text {criteria }}=$ & $w_{2}$ & \multicolumn{5}{c}{$w_{1}$} \\
\hline & 0.0000 & 0.8750 & 0.9000 & & 0.60538 & 0.35258 \\
& 0.8333 & 0.0000 & 0.1000 & $*$ & 0.10314 & $=0.53363$ \\
& 0.1667 & 0.1250 & 0.0000 & & 0.29148 & 0.11379 \\
\hline
\end{tabular}


So, the weights of criteria are changed from 0.60538 to $0.3526,0.10314$ to 0.5336 , and 0.29148 to 0.1138 for the weight values of criteria $\mathrm{C} 1, \mathrm{C} 2$ and $\mathrm{C} 3$ respectively.

Step 5: The local weights of the sub-criteria are determined using pair-wise comparison matrix. The three sub-criteria comparisons with respect to criteria $\mathrm{C} 1, \mathrm{C} 2$, and $\mathrm{C} 3$ are shown in Table 7, Table 8 and Table 9 respectively.

Table 7. Pair-wise comparison matrix of sub-criteria with respect to $\mathrm{C} 1$

\begin{tabular}{ccccll}
\hline $\mathrm{C} 1$ & $\mathrm{C} 11$ & $\mathrm{C} 12$ & $\mathrm{C} 13$ & Row Sum & Weight \\
\hline $\mathrm{C} 11$ & 1 & $1 / 7$ & $1 / 5$ & 1.3429 & 0.0719 \\
$\mathrm{C} 12$ & 7 & 1 & 3 & 11.0000 & 0.5890 \\
$\mathrm{C} 13$ & 5 & $1 / 3$ & 1 & 6.3333 & 0.3391 \\
\hline & & & & 18.6762 & 1.0000 \\
\hline
\end{tabular}

Table 8. Pair-wise comparison matrix of sub-criteria with respect to $\mathrm{C} 2$

\begin{tabular}{llrrll}
\hline $\mathrm{C} 2$ & $\mathrm{C} 21$ & $\mathrm{C} 22$ & $\mathrm{C} 23$ & Row Sum & Weight \\
\hline $\mathrm{C} 21$ & 1 & $1 / 3$ & $1 / 7$ & 1.4762 & 0.0790 \\
$\mathrm{C} 22$ & 3 & 1 & $1 / 5$ & 4.2000 & 0.2249 \\
$\mathrm{C} 23$ & 7 & 5 & 1 & 13.0000 & 0.6961 \\
\hline & & & & 18.6762 & 1.0000 \\
\hline
\end{tabular}

Table 9. Pair-wise comparison matrix of sub-criteria with respect to $\mathrm{C} 3$

\begin{tabular}{llrrll}
\hline C3 & C31 & C32 & C33 & Row Sum & Weight \\
\hline C31 & 1 & $1 / 3$ & $1 / 4$ & 1.5833 & 0.0900 \\
C32 & 3 & 1 & $1 / 3$ & 4.3333 & 0.2464 \\
C33 & 4 & 3 & 1 & 8.0000 & 0.4550 \\
\hline & & & & 17.5833 & 1.0000 \\
\hline
\end{tabular}

The normalized weights are obtained by analyzing the matrix.

\begin{tabular}{lrrr}
\hline & $\mathrm{C} 11$ & 0.0719 \\
\hline$w_{\text {sub-criteria (economic aspect) }}=$ & $\mathrm{C} 12=0.5890$ \\
& $\mathrm{C} 13=0.3391$ \\
& $\mathrm{C} 21=0.0790$ \\
$w_{\text {sub-criteria (technological aspect) }}=$ & $\mathrm{C} 22=0.2249$ \\
& $\mathrm{C} 23=0.6961$ \\
& $\mathrm{C} 31=0.0900$ \\
$w_{\text {sub-criteria (environment aspect) }}=$ & $\mathrm{C} 32=0.2464$ \\
& $\mathrm{C} 33=0.4550$ \\
\hline
\end{tabular}

Step 6: The overall weights of the sub-criteria are computed by multiplying interdependent weights of criteria as in Step 4 with local weights of sub-criteria in Step 5. It is shown in the following matrices.

\begin{tabular}{|c|c|c|c|c|c|c|}
\hline & & $\left(w_{\text {criteria }}\right)$ & & $\left(w_{\text {economic aspect }}\right)$ & & \\
\hline $\mathrm{C} 11$ & & 0.35258 & & 0.0719 & & 0.0254 \\
\hline $\mathrm{C} 12$ & $=$ & 0.53363 & & 0.5890 & $=$ & 0.3143 \\
\hline $\mathrm{C} 13$ & & 0.11379 & & 0.3391 & & 0.0386 \\
\hline & & $\left(w_{\text {criteria }}\right)$ & & $\left(w_{\text {technological aspect }}\right)$ & & \\
\hline $\mathrm{C} 21$ & & 0.35258 & & 0.0790 & & 0.0279 \\
\hline $\mathrm{c} 22$ & $=$ & 0.53363 & $*$ & 0.2249 & $=$ & 0.1200 \\
\hline $\mathrm{C} 23$ & & 0.11379 & & 0.6961 & & 0.0792 \\
\hline
\end{tabular}




\begin{tabular}{|c|c|c|c|c|c|}
\hline & & $\left(w_{\text {criteria }}\right)$ & & $\left(w_{\text {environment aspect }}\right)$ & \\
\hline C31 & & 0.35258 & & 0.0900 & 0.0317 \\
\hline C32 & $=$ & 0.53363 & * & 0.2464 & 0.1315 \\
\hline $\mathrm{C} 33$ & & 0.11379 & & 0.4550 & 0.0518 \\
\hline
\end{tabular}

The weighted sub-criteria and overall weighted sub-criteria are shown in Table 10.

Table 10. Overall weights of sub-criteria

\begin{tabular}{lllll}
\hline Criteria & $\begin{array}{l}\text { Weighte } \\
\text { d criteria }\end{array}$ & $\begin{array}{l}\text { Sub-criteria of } \\
\text { C1, C2 and C3 }\end{array}$ & $\begin{array}{l}\text { Un-weighted } \\
\text { Sub-criteria } \\
\text { (Weight of sub-criteria) }\end{array}$ & $\begin{array}{l}\text { Weighted Sub-criteria (global) } \\
\text { (Overall weight of sub-criteria) }\end{array}$ \\
\hline C1 & 0.2594 & C11 & 0.0719 & 0.0254 \\
& & C12 & 0.5890 & 0.3143 \\
& & C13 & 0.3391 & 0.0386 \\
C2 & 0.0147 & C21 & 0.0790 & 0.0279 \\
& & C22 & 0.2249 & 0.1200 \\
& & C23 & 0.6961 & 0.0792 \\
C3 & 0.1249 & C31 & 0.0900 & 0.0317 \\
& & C32 & 0.2464 & 0.1315 \\
& & C33 & 0.4550 & 0.0518 \\
\hline
\end{tabular}

Step 7: The weight of alternatives with respect to each sub-criterion is computed. The $w_{4}$ is computed and results are shown in Table 11.

Table 11. Weights of alternatives with respect to sub-criteria

\begin{tabular}{lllllllllll}
\hline & & C11 & C12 & C13 & C21 & C22 & C23 & C31 & C32 & C33 \\
\hline \multirow{3}{*}{$w_{4}$} & A1 & 0.1031 & 0.4260 & 0.1020 & 0.6961 & 0.0719 & 0.1236 & 0.3929 & 0.3699 & 0.1031 \\
& A2 & 0.2915 & 0.4709 & 0.8980 & 0.0790 & 0.3391 & 0.1269 & 0.1071 & 0.1370 & 0.2915 \\
& A3 & 0.6054 & 0.1031 & 0.2901 & 0.2249 & 0.5890 & 0.7496 & 0.5000 & 0.4932 & 0.6054 \\
\hline
\end{tabular}

Step 8: The overall weight of alternatives in terms of inter-relationship within sub-criteria are computed as follows;

\begin{tabular}{lllllll}
\hline \multicolumn{3}{c}{$\mathrm{A} 1$} & & & 0.2447 \\
\hline$w_{\text {alternatives }}=$ & $\mathrm{A} 2$ \\
& $\mathrm{~A} 3$
\end{tabular}

The overall relative weights of alternatives indicate the prioritization of the ideal WWT technology. The prioritization of alternatives is ranked in ascending order,

$$
\text { Composting (0.3074) } \quad \rightarrow \quad \text { Phytoremediation (0.2795) } \quad \rightarrow \quad \text { AnaerobicDigestion (0.2447) }
$$

Based on the overall relative weights, it is shown that the best WWT technology is composting followed by phytoremediation and anaerobic digestion.

\section{Conclusions}

The aim of this paper was to propose a prioritization in real case experiment for solving the wastewater treatment technology decision problem. Selecting the wastewater technology is a complicated issue which multi dependence criteria must be considered concurrently. Thus, the analytic network process with the capability of unifying inner dependence and outer dependence among criteria was applied to explore the decision process and suggesting the relative weights of the technology alternatives. The analytic network process has included the weights of sub-criteria and criteria in proposing the final overall relative weights of alternatives. The multiplications of criteria weights and sub-criteria weights was utilized to obtain the final overall relative weights of alternatives. The technology of composting with the overall relative weight of 0.3074 was the most prioritized choice among all the three alternatives. The second prioritized choice in wastewater technology selection was Phytoremediation with 
the overall relative weight 0.2795 followed by anaerobic digestion with the overall relative weight 0.2447 . The analytic network process was successfully identified 'composting' as the ideal technology in wastewater treatment in Terengganu Malaysia. The paper has highlighted a new insight into a decision making method that based on a network to propose weights and prioritization for WWT technology alternatives. However, this proposed preference method warrants further investigations, especially in the aspects of validity and reliability of the experiment. Further research with some other real case experiments would further enhance the robustness of the analytic network process. Comparative study and sensitivity analysis are some of the possible validation tools that can be explored in future research direction.

\section{References}

Abdullah, L. (2015). Developing decision on suitable wastewater treatment technology using fuzzy simple additive weighting. International Journal of Engineering and Technology, 7, 405-413. Retrieved from http://www.enggjournals.com/ijet/docs/IJET15-07-02-302.pdf

Agarwal, A., Shankar, R., \& Tiwari, M. K. (2006). Modelling the metrics of lean, agile and leagile supply chain: an ANP-based approach. European Journal of Operational Research, 173, 211-225. Retrieved from http://www.sciencedirect.com/science/article/pii/S0377221705000135

Banar, M., Kose, B. M., Ozkan, A., \& Acar, I. P. (2007). Choosing a municipal landfill site by analytic network process. Environmental Geology, 52, 747-751. Retrieved from $\mathrm{http} / / /$ link.springer.com/article/10.1007/s00254-006-0512-x

Bottero, M., \& Mondini, G. (2008). An appraisal of analytic network process and its role in sustainability assessment in Northern Italy. International Journal of Management of Environmental Quality, 19, 642-660. Retrieved from http://www.emeraldinsight.com/doi/abs/10.1108/14777830810904885

Bottero, M., Comino E., \& Riggio, V. (2011). Application of the Analytic Hierarchy Process and the Analytic Network Process for the assessment of different wastewater treatment systems. Environmental Modelling and Software, 26, 1211-1224. Retrieved from http://www.sciencedirect.com/science/article/pii/S1364815211001009

Figueira, J., Greco, S., \& Ehrgott, M. (2005). Multiple Criteria Decision Analysis, State of the Art Survey. New York: Springer.

Ilangkumaran, M., Sasirekha, V., Anojkumar, L., Sakthivel, G., Raja, M. B. R., \& Kumar, T. R. S. (2013). Optimization of wastewater treatment technology selection using hybrid MCDM. Management of Environmental Quality, 24, 619-641. $\quad$ Retrieved from http://www.emeraldinsight.com/doi/full/10.1108/MEQ-07-2012-0053

Kalbar, K. P., Karmakar, S., \& Asolekar, S. R. (2012). Selection of an appropriate wastewater treatment technology: A scenario-based multiple-attribute decision-making approach. Journal of Environmental Management, $\quad 113(20), \quad 158-169 . \quad$ Retrieved $\quad$ from http://www.sciencedirect.com/science/article/pii/S0301479712004331

Khan, S., \& Faisal, M. N. (2008). An analytic network process model for municipal solid waste disposal options. Waste Management, 28, 1500-1508. Retrieved from http://www.sciencedirect.com/science/article/pii/S0956053X07002310

Molinos-Senante, M., Go'mez, T., Garrido-Baserba, M., Caballero, R., \& Sala-Garrido, R. (2014). Assessing the sustainability of small wastewater treatment systems: A composite indicator approach, Science of the Total Environment, $\quad 497-498, \quad 607-617.60$ Retrieved http://www.sciencedirect.com/science/article/pii/S0048969714011930

Neaupane, K. M., \& Piantanakulchai M. (2006). Analytic network process model for landslide hazard zonation. Engineering Geology, 85, 281-294. Retrieved from http://www.sciencedirect.com/science/article/pii/S0013795206001001

Niemura, M. P., \& Saaty, T. L. (2004). An analytic network process model for financial-crisis forecasting. International Journal of Forecasting, 20, 573-587. Retrieved from http://www.sciencedirect.com/science/article/pii/S0169207003001110

Plakas, K. V., Karabelas, A. J., \& Georgiadis, A. A. (2016). Sustainability assessment of tertiary wastewater treatment technologies: A multi-criteria analysis. Water Science and Technology, 73, 1532-1540. Retrieved from https://www.ncbi.nlm.nih.gov/pubmed/27054724 
Promentilla, M., Furuichi, T., Ishii, K., \& Tanikawa, N. (2006). Evaluation of Remedial Countermeasures Using The Analytic Network Process. Waste Management, 26, 1410-1421. Retrieved from http://www.sciencedirect.com/science/article/pii/S0956053X0500317X

Ross and Associates Environmental Consulting, Ltd. (2012). Planning and Sustainability-A handbook for Water and Wastewater Utilities. United States Environmental Protection Agency. Retrieved from http://efcnetwork.org/publication/planning-and-sustainability-a-handbook-for-water-and-wastewater-utilitie $\mathrm{s} /$

Saaty, T. (1996). Decision making with dependence and feedback: The analytic network process, RWS Publications, Pittsburgh.

Tuzkaya, G. Onut, S. Tuzkaya, U. R., \& Gulsun, B. (2008). An analytic network process approach for locating undesirable facilities: An example from Istanbul, Turkey. Journal of Environmental Management, 88, 970-983. Retrieved from http://www.sciencedirect.com/science/article/pii/S0301479707001879

Ulutas, B. H. (2005). Determination of the appropriate energy policy for Turkey. Energy, 30, 1146-1161.

Wolfslehner, B., \& Vacik, H. (2008). Evaluating sustainable forest management strategies with the analytic network process in a pressure-state-response framework. Journal of Environmental Management, 88, 1-10. Retrieved from http://www.sciencedirect.com/science/article/pii/S0301479707000618

Yuksel, I., \& Dagdeviren, M. (2007). Using Analytic network process (ANP) in a SWOT analysis: A case study for a textile firm. Information Sciences, 177, 3364-3382. Retrieved from http://www.sciencedirect.com/science/article/pii/S0020025507000230

\section{Copyrights}

Copyright for this article is retained by the author(s), with first publication rights granted to the journal.

This is an open-access article distributed under the terms and conditions of the Creative Commons Attribution license (http://creativecommons.org/licenses/by/4.0/). 